AperTO - Archivio Istituzionale Open Access dell'Università di Torino

\title{
Catheter-tissue contact force values do not impact mid-term clinical outcome following pulmonary vein isolation in patients with paroxysmal atrial fibrillation.
}

\section{This is the author's manuscript}

Original Citation:

Availability:

This version is available http://hdl.handle.net/2318/157099

since

Published version:

DOI:10.1007/s10840-014-9947-2

Terms of use:

Open Access

Anyone can freely access the full text of works made available as "Open Access". Works made available under a Creative Commons license can be used according to the terms and conditions of said license. Use of all other works requires consent of the right holder (author or publisher) if not exempted from copyright protection by the applicable law. 


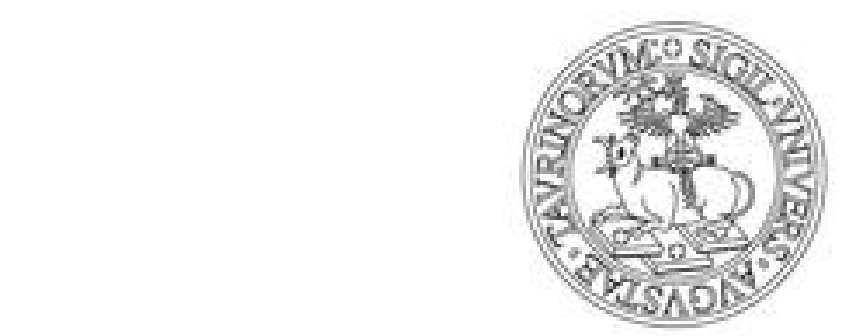

\section{UNIVERSITÀ DEGLI STUDI DI TORINO}

This is an author version of the contribution published on:

Stabile G,Solimene F,Calo L,Anselmino M,Castro A,Pratola C,Golia P,Bottoni N,Grandinetti G,De Simone A,Schillaci V,Bertaglia E,De Ponti R Catheter-tissue contact force values do not impact mid-term clinical outcome following pulmonary vein isolation in patients with paroxysmal atrial fibrillation.

JOURNAL OF INTERVENTIONAL CARDIAC ELECTROPHYSIOLOGY (2015) 42

DOI: $10.1007 / \mathrm{s} 10840-014-9947-2$

The definitive version is available at:

http://link.springer.com/content/pdf/10.1007/s10840-014-9947-2 
Catheter-tissue contact force values do not impact mid-term clinical outcome following pulmonary veins isolation in patients with paroxysmal atrial fibrillation.

Giuseppe Stabile ${ }^{1}, \mathrm{MD}$, Francesco Solimene ${ }^{2}, \mathrm{MD}$, Leonardo Calò $^{3}, \mathrm{MD}$, Matteo Anselmino ${ }^{4}, \mathrm{MD}$, Antonello Castro ${ }^{5}, \mathrm{MD}$, Claudio Pratola ${ }^{6}, \mathrm{MD}$, Paolo Golia ${ }^{7}, \mathrm{MD}$, Nicola Bottoni ${ }^{8}, \mathrm{MD}$, Giuseppe Grandinetti $^{9}, \mathrm{MD}$, Antonio De Simone ${ }^{10}, \mathrm{MD}$, Vincenzo Schillaci ${ }^{1}, \mathrm{MD}$, Emanuele Bertaglia ${ }^{11}, \mathrm{MD}$, Roberto De Ponti ${ }^{12}$.

1Clinica Mediterranea, Napoli; 2Clinica del Sole, Salerno; 3Policlinico Casilino, Roma; 4Città della Salute e della Scienza, Department of Medical Sciences, University of Turin; 5Ospedale Sandro Pertini, Roma; 6Ospedale Sant'Anna, Ferrara; 7Ospedale Morgagni, Forlì; 8Azienda Ospedaliera Santa Maria Nuova, Reggio Emilia; 9Policlinico Universitario, Bari; 10Clinica San Michele, Maddaloni (CE); 11 Clinica Cardiologica, Dipartimento di Scienze Cardiologiche, Toraciche e Vascolari, Università di Padova; 12 Ospedale di Circolo e Fondazione MacchiUniversity of Insubria, Varese, Italy.

\section{Contact force catheter in PV ablation}

Address for correspondence:

Giuseppe Stabile,

Laboratorio di Elettrofisiologia,

Clinica Mediterranea, Via Orazio 2, 80122 Napoli

Tel 0039817259641

Fax 0039817259777

E-mail gmrstabile@tin.it 


\begin{abstract}
Purpose. Catheter-tissue contact is critical for effective lesion creation in radiofrequency catheter ablation (RFCA). In a multicenter prospective study, we assessed the relationship between catheter contact force (CF) during RFCA for paroxysmal atrial fibrillation (AF) and clinical recurrences over a mid-term follow-up.

Methods. All patients underwent RFCA for paroxysmal AF by antral pulmonary vein (PV) isolation, aiming at entry and exit conduction block in all PVs. A new open-irrigated tip catheter with CF sensing (SmartTouch ${ }^{\mathrm{TM}}$, Biosense Webster Inc. CA) was used. All patients were followed for at least 12 months and the relationship between CF and clinical outcomes assessed.

Results. One year follow-up was available in 92/95 of the patients enrolled. Acute PVI was achieved in $100 \%$ of the veins. Mean CF during RFCA was $12.2 \pm 3.9 \mathrm{~g}$. Mean Force Time Integral (FTI) was $733 \pm 505$ gs. Following the 3-month blanking period, $17(18 \%)$ patients experienced at least 1 atrial tachyarrhythmia relapse. There was no statistical difference in mean CF $(13 \pm 3.4 \mathrm{~g}$ vs $12 \pm 4 \mathrm{~g}, \mathrm{p}=0.32)$ and mean FTI $(713 \pm 487 \mathrm{gs}$ vs $822 \pm 590 \mathrm{gs}, \mathrm{p}=0.42)$ between patients with and without arrhythmias recurrences. Recurrences were recorded in $22 \%$ of patients achieving a mean FTI value below the median of 544 gs and in $15 \%$ of patients with a mean FTI value above the median $(\mathrm{p}=0.64)$.
\end{abstract}

Conclusions. RFCA with CF data during PV isolation for paroxysmal AF improves physician's knowledge on catheter-tissue contact. In the present dataset, however, higher CF values did not impact mid-term clinical RFCA outcome.

Key words: catheter ablation, atrial fibrillation, contact force 


\section{INTRODUCTION}

The creation of a durable radiofrequency (RF) lesion depends on several parameters, including catheter tip electrode size, temperature, orientation, RF pulse duration, power, blood flow, and catheter to tissue contact (1-4). The wide diffusion of open irrigated catheters (5-8) has reduced the role of temperature in monitoring RF lesion formation. Recently development of new contact force (CF) sensor catheters has alowed measurement of the tip to tissue CF during the RF ablation procedure. Optimization of electrode-tissue contact during RF catheter ablation for pulmonary veins (PV) isolation impacts on procedure parameters by significantly reducing procedure and fluoroscopy times, without increasing acute complications (9-11). Preliminary data suggest a potential benefit of real-time CF sensing technology in reducing atrial fibrillation (AF) recurrence during the first year after PV isolation $(11,12)$. The aim of this multicenter prospective study was to assess the relationship between catheter $\mathrm{CF}$ during RF catheter ablation for paroxysmal $\mathrm{AF}$ and clinical recurrences during a mid-term follow-up.

\section{METHODS}

Patients' selection. As previously described (10) this multicenter prospective study enrolled 95 patients in 9 Italian centres (see the Appendix) for a 3-month period. Patients aged between 18 and 90 years with documented symptomatic AF episodes refractory to drug therapy (Class I or III drugs) and self-terminating within 7 days were included.

This study followed the principles outlined in latest update of the Declaration of Helsinki and all patients signed informed consents.

Ablation procedure and contact force measuring. Detailed ablation procedure and CF measuring has been previously described (10). Briefly, after transseptal catheterization, 3D electroanatomic maps of the left atrium and PVs were reconstructed using a nonfluoroscopic navigation system (CARTO $3^{\circledR}$, version 2, Biosense Webster Inc., Diamond Bar, California, USA) $(7,13)$. Maps were acquired during AF or sinus rhythm using respiratory gating. Fast anatomic mapping or imaging 
integration with a pre-acquired computed tomography or magnetic resonance scan was used, according to operators' preference. RF pulses were delivered using the 3.5-mm Thermocool SmartTouch $^{\mathrm{TM}}$ (Biosense Webster, Inc., Diamond Bar, CA, USA) in power control mode. RF power was set between 30 and $35 \mathrm{~W}$ depending on different left atrial sites and the catheter tip was irrigated by saline at a flow rate of $2 \mathrm{~mL} / \mathrm{min}$ during mapping and of $30 \mathrm{~mL} / \mathrm{min}$ during ablation. RF was delivered up to 60 seconds or until local electrogram amplitude was reduced $>80 \%$ to produce a circumferential lesion around the proximal part of each PV's ostium or around ipsilateral PVs according to anatomy. The lesion around the PV ostium was created by sequential point-bypoint application of RF energy or by continuously dragging the catheter, according to operators' preference. A circular decapolar or duodecapolar mapping catheter (LASSO ${ }^{\circledR}$, Biosense Webster Inc, Diamond Bar, CA, USA) was used to confirm PV electrical isolation with demonstration of entry and exit block. Resumption of left atrium to PV conduction was evaluated for 30 minutes after ablation. In case of reconnection, PVs were newly isolated targeting the residual electrical breakthroughs.

Operators involved in this study had previous experience in the use of Thermocool SmartTouch ${ }^{\mathrm{TM}}$ catheter in a 6-month period prior to study commencement, and they were encouraged to navigate the catheter with a limited use of fluoroscopy.

The real time visualization of the CF values, during both the mapping and ablation phase, was available. During RF delivery, it was recommended to make every effort to reach and maintain a displayed CF value between 10 and $40 \mathrm{~g}$.

For all ablation sites, CF data were recorded and exported after the procedure for off-line analysis. During each RF application maximum, minimum, and mean CT values, obtained by averaging values sampled every $50 \mathrm{~ms}$, were stored and subsequently analysed. Force Time Integral (FTI) expressed in $\mathrm{g}^{*} \mathrm{~s}$ and defined as the integral of the CF-time curve during the ablation period in which the catheter was located in the segment of interest was also calculated and analysed. 
Follow-up. After discharge patients were followed for 12 months, with a clinical visit and a 12-lead electrocardiogram scheduled at 1, 3, 6, and 12 months. In addition, a 24-hour Holter monitoring was obtained at 3 and 12 months. Moreover, patients were instructed to obtain an ECG in the event of palpitations. No antiarrhythmic medication was prescribed following ablation.

If there was documented recurrence of symptomatic $\mathrm{AF}$ and the patient required antiarrhythmic drug therapy, a previously ineffective but tolerated class 1 or class 3 (sotalol) drug was the preferred option.

Ablation was deemed successful in the absence of symptomatic or asymptomatic atrial tachyarrhythmias lasting more than 30 seconds identified on surface ECG or on Holter monitoring, off antiarrhythmic drug therapy. As early relapse of atrial tachyarrhythmias within the first 3 months after RF ablation may be a transient phenomenon, this transition period was excluded from the final analysis (14).

Statistical analysis. Normally distributed continuous variables were expressed as mean $( \pm \mathrm{SD})$ and compared by unpaired Student's $t$ test. Skewed variables were expressed as median (25-75 quartiles) and compared by the runk-sum test. Normality was assessed by the Shapiro-Wilk test. Categorical variables were presented as counts and percentages, and compared by Chi square test (Pearson, Yates or Fisher's exact test as appropriate). The actuarial probability of freedom from AF after ablation was calculated using the Kaplan-Meier method . Differences between the curves were tested for significance by the log-rank statistic. A p value $<0.05$ was considered statistically significant.

\section{RESULTS}

Procedural data. Complete one year follow-up was available in 92/95 (97\%) patients; three patients were lost after 6 months of follow-up. All patients underwent successful ablation achieving acute PV isolation in $100 \%$ of the veins. Overall procedure time, fluoroscopy time, and ablation time were $138 \pm 67,14.3 \pm 11.2$ and $34 \pm 20 \mathrm{~min}$, respectively. Mean CF during ablation was 
12.2 \pm 3.9 g. Mean FTI was $733 \pm 505 \mathrm{gs}$. Three groin haematoma were observed. No stroke/TIA, pericardial effusion, or cardiac tamponade were reported within 30 days from the procedure.

Clinical outcome. Following the 3-month blanking period, 17 (18\%) patients experienced at least 1 episode of atrial tachyarrhythmia. In Table I are summarized the clinical characteristics of the study population, there was no statistical difference between patients with and without arrhythmias recurrences with the exception of an higher prevalence of recurrences among females. Comparing radiofrequency energy applications between the group of patients with and the one without recurrences, there was no statistical difference in mean CF $(13 \pm 3.4 \mathrm{~g}$ vs $12 \pm 4 \mathrm{~g}$, respectively; $\mathrm{p}=0.32)$ and mean FTI $(713 \pm 487$ gs vs $822 \pm 590$ gs, respectively; $\mathrm{p}=0.42)$. In Table II are reported the percentages of CF values 5-10g, 11-20g, and 21-30g, in patients with and without AF recurrences percentage. There was no difference in the percentage of CF values among patients with and without AF recurrence when the suggested minimum value of $10 \mathrm{~g}$ was achieved. Similarly, there was no statistically significant difference in the median value of mean CF [12 (9.822) g vs $11.1(6.7-23.7) \mathrm{g}, \mathrm{p}=0.64]$ and FTI [520 (361-2065) gs vs 561 (143-2724) gs, p=0.51] values in patients with vs those without recurrences. Arrhythmias recurrences were recorded in $22 \%$ of patients achieving a mean FTI value below the median of 544 gs against $15 \%$ of patients with a mean FTI value above the median ( $\mathrm{p}=0.64)$. Figure 1 shows the Kaplan-Meier survival curve of patients free arrhythmia recurrences during the 12-month follow-up according to FTI quartiles. No statistically significant difference was observed among the four groups $(\mathrm{p}=0.43)$.

\section{DISCUSSION}

Main findings. In this multicenter study on the use of a new technology which allows visualization of $\mathrm{CF}$ values and $\mathrm{CF}$ direction, performed with operators not blinded to $\mathrm{CF}$ values, higher cathetertissue CF values, achieved during PV isolation for paroxysmal AF, did not significantly impact mid-term clinical outcome. 
Previous studies. Preliminary experience of RF catheter ablation in patients with AF by means of catheters able to assess catheter-tissue contact, by means of optical fibers, impedance measurement, and magnetic sensors, have shoved how higher FTI and mean CF values during ablation allow reduction of both procedural and fluoroscopy time (9-11), without increasing complications. Moreover, $\mathrm{CF}$ data allowed the identification of key areas where $\mathrm{CF}$ was poor, related to higher probability of acute and sub-acute reconnection $(15,16)$. Availability of real time CF information during PVI has been associated with a significantly lower acute and 3-month PV reconnection rate. In the TOCCATA study (12) 32 patients with paroxysmal AF underwent PV isolation by using a RF ablation catheter with a CF sensor integrated at its tip, and they were followed for 12 months. All patients treated with an average $\mathrm{CF}$ of $<10 \mathrm{~g}$ ( 5 of 5 patients) experienced recurrences, whereas $80 \%$ of the patients treated with an average CF of $>20 \mathrm{~g}$ ( 8 of 10 patients) were free from AF recurrence at 12 months. The analysis of the average force-time integral showed that $75 \%$ of the patients treated with $<500$ gs were recurrent whereas only $31 \%$ of the patients treated with $>1000$ gs had recurrences at 12 months. The authors, based on this small population, concluded that CF during catheter ablation for AF related to RFCA clinical outcome. Marijon et al (11) first demonstrated the benefit of CF technology use in reducing AF recurrence during the year following PVI, when compared to a non-CF catheter. Sixty patients with symptomatic paroxysmal AF were enrolled in this prospective trial, comparing circular antral catheter ablation using either the $\mathrm{CF}$ catheter used in the present study (CF group) or a non-CF open-irrigated catheter (control group). The incidence rates of AF recurrence were $10.5 \%$ (95\% CI, 1.38-22.4) in the CF group, and 35.9\% (95\% CI, 12.4-59.4) in the control group $(\mathrm{p}=0.04)$. After adjustment of potential confounders, the use of CF catheter was found to be associated with a lower AF recurrence (OR 0.18, 95\% CI 0.040.94, $\mathrm{p}=0.04)$

Present study. For the first time in a multicenter experience, our data demonstrates that CF improves physician's knowledge on Catheter-tissue contact reducing procedure and fluoroscopy 
times, but not significantly impact on mid-term clinical outcome. Only a trend towards a better outcome in patients with mean FTI values above the median value was observed. Many factors might explain the discrepancy of our results compared to previous published data. 1) Although there is a growing evidence that catheter-tissue $\mathrm{CF}$ is a major determinant for RF ablation lesion size and quality, Olson et al.(4) demonstrated equivalent ablation lesion size with RF energy delivered with intermittent tissue contact over a longer period of time when compared to lesions created with constant catheter contact. This hypothesis seems to be confirmed by the findings $(9,11)$ that CF guided ablation decreased RF time as compared with ablation performed with standard catheters. Also in our experience (10) optimization of electrode-tissue contact during RF catheter ablation for PV isolation significantly reduced procedure and fluoroscopy times. In fact, increasing RF energy duration in case of low or unknown contact may lead to similar clinical results. 2) In our study operators were not blinded to the CF value and, during RF delivery, it was recommended to make the maximum effort to reach and maintain a displayed CF value between 10 and $40 \mathrm{~g}$. In fact, mean CF during ablation was $12.2 \pm 3.9 \mathrm{~g}$, higher than that $(<10 \mathrm{~g})$ predicting poor outcome in previous studies (Reddy et al (12)). 3) One of the advantages of CF technology is the possibility to visualize real time direction and orientation of the catheter's tip enabling immediate recognition of catheter dislodgement/sliding (11). This feature is independent from CF value and unmeasurable in a routine clinical setting.

\section{Limitations.}

The number of patients enrolled in each centre was limited and this might increase the range of data variability, and the bias of operators' dependent outcome. However, this observational prospective study is the largest to date available and provides a representative picture of the real-life scenario of the use of CF sensing for AF ablation. Larger cohorts are needed to confirm or exclude the trends observed in the present study.

Another potential limitation of the study was the different techniques used to perform PVI. Infact the lesions around the PV ostium were created by sequential point-by-point application of RF 
energy or by continuously dragging the catheter, according to operators' preference. We did not evaluated the interlesion distance with both approaches. Recently, Park et al (17) demonstrated that acutely durable PV isolation can be achieved when RF lesions are delivered with a mean $\mathrm{CF}>10 \mathrm{~g}$ and an interlesion distance $<5 \mathrm{~mm}$.

Conclusions. RFCA with CF data during PV isolation for paroxysmal AF improves physician's knowledge on Catheter-tissue contact. In the present dataset, however, higher CF values did not impact mid-term clinical RFCA outcome. Further studies randomly comparing implementation or not of CF data on RFCA outcome are therefore needed.

Conclict if interest disclosure: dr. Roberto De Ponti is a consultant of Biosense Webster; dr Emanuele Bertaglia is a consultant of Biosense Webster, St. Jude Medical, and Boston Scientific; none for the other authors. 


\section{REFERENCES}

1. Haines D. Determinants of lesion size during radiofrequency catheter ablation: the role of electrode-tissue contact pressure and duration of energy delivery. J Cardiovasc Electrophysiol $1991 ; 2: 509-515$.

2. Avitall B, Mughal K, Hare J, Helms R, Krum D. The Effects of Electrode-Tissue Contact on Radiofrequency Lesion Generation. Pace Clin Electrophysiol. 1997;20[Pt. 11:2899-910).

3. Thiagalingam A, D’Avila A, Floley L, Guerrero JL, Lambert H, Leo G, Ruskin JN, Reddy VY. Importance of Catheter Contact Force During Irrigated Radiofrequency Ablation:Evaluation in a Porcine Ex Vivo Model Using a Force-Sensing Catheter. J Cardiovasc Electrophysiol. 2010;21:806-11.

4. Olson MD, Phreaner N, Schuller JL, Nguyen DT, Katz DF, Aleong RG, Tzou WS, Sung R, Varosy PD, Sauer WH. Effect of catheter movement and contact during application of radiofrequency energy on ablation lesion characteristics. J Interv Card Electrophysiol. 2013; 38:123-9.

5. Waldo AL, Wilber DJ, Marchlinski FE, Stevenson WG, Aker B, Ming Boo L, Jackman WM. Safety of the open-irrigated catheter for radiofrequency ablation: safety analysis from six clinical studies. Pace Clin Electrophysiol. 2012;35:1081-1089.

6. Scaglione M, Blandino A, Raimondo C, Caponi D, Di Donna P, Toso E, Ebrille E, Cesarani F, Ferrarese E, Gaita F. Impact of ablation catheter irrigation design on silent cerebral embolism after radiofrequency catheter ablation of atrial fibrillation: results from a pilot study. $\mathrm{J}$ Cardiovasc Electrophysiol. 2012;23:801-5.

7. Bertaglia E, Fassini G, Anselmino M, Stabile G, Grandinetti G, De Simone A, Calò L, Pandozi C, Pratola C, Zoppo F, Tondo C, Iuliano A, Gaita F. Comparison of ThermoCool(®) Surround Flow Catheter Versus ThermoCool(@) Catheter in Achieving Persistent Electrical Isolation of Pulmonary Veins: A Pilot Study. J Cardiovasc Electrophysiol. 2013;24:269-73. 
8. Stabile G, Bertaglia E, Pappone A, Themistoclakis S, Tondo C, Calzolari V, Bottoni N, Arena G, Rebellato L, Del Greco M, De Simone A, Corò L, Avella A, Anselmino M, Pappone C. Low incidence of permanent complications during catheter ablation for atrial fibrillation using open irrigated catheters: a multicenter registry. Europace. 2014;16:1154-9.

9. Martinek M, Lemes C, Sigmund E, Derdorfer M, Aichinger J, Winter S, Nesser HJ, Pürerfellner H. Clinical Impact of a New Open-Irrigated Radiofrequency Catheter with Direct Force Measurement on Atrial Fibrillation Ablation. Pace Clin Electrophysiol. 2012;35:1312-8.

10. Stabile G, Solimene F, Calò L, Anselmino M, Castro A, Pratola C, Golia P, Bottoni N, Grandinetti G, De Simone A, De Ponti R, Dottori S, Bertaglia E. Catheter-tissue contact force for pulmonary veins isolation: a pilot multicentre study on effect on procedure and fluoroscopy time. Europace. 2014;16:335-40.

11. Marijon E, Fazaa S, Narayanan K, Guy-Moyat B, Bouzeman A, Providencia R, Treguer F, Combes N, Bortone A, Boveda S, Combes S, Albenque JP. Real-Time Contact Force Sensing for Pulmonary Vein Isolation in the Setting of Paroxysmal Atrial Fibrillation: Procedural and 1Year Results. J Cardiovasc Electrophysiol. 2013 Oct 8. doi: 10.1111/jce.12303. [Epub ahead of print]

12. Reddy VY, Shah D, Kautzner J, Schmidt B, Saoudi N, Herrera C, Jaïs P, Hindricks G, Peichl P, Yulzari A, Lambert H, Neuzil P, Natale A, Kuck KH. The relationship between contact force and clinical outcome during radiofrequency catheter ablation of atrial fibrillation in the TOCCATA study. Heart Rhythm. 2012;9:1789-95.

13. Stabile G, Scaglione M, Del Greco M, De Ponti R, Bongiorni MG, Zoppo F, Soldati E, Marazzi R, Marini M, Gaita F, Iuliano A, Bertaglia E. Reduced fluoroscopy exposure during ablation of atrial fibrillation using a novel electroanatomical navigation system: A multicentre experience. Europace 2012;14:60-65. 
14. Bertaglia E, Stabile G, Senatore G, Zoppo F, Turco P, Amellone C, De Simone A, Fazzari M, Pascotto P. Predictive value of early atrial fibrillation recurrence after circumferential pulmonary vein ablation. Pace and Clinical Electrophysiology 2005;28:366-71.

15. Haldar S, Jarman JW, Panikker S, Jones DG, Salukhe T, Gupta D, Wynn G, Hussain W, Markides V, Wong T. Contact force sensing technology identifies sites of inadequate contact and reduces acute pulmonary vein reconnection: A prospective case control study. Int J Cardiol. 2013;168:1160-6.

16. Neuzil P, Reddy VY, Kautzner J, Petru J, Wichterle D, Shah D, Lambert H, Yulzari A, Wissner $\mathrm{E}, \mathrm{Kuck} \mathrm{KH}$. Electrical reconnection after pulmonary vein isolation is contingent on contact force during initial treatment: results from the EFFICAS I study. Circ Arrhythm Electrophysiol. 2013;6:327-33.

17. Park CL, Lehrmann H, Keyl C, Weber R, Schiebeling J, Allgeier J, Schurr P, Shah A, Neumann FJ, Arentz T, Jadidi AS. Mechanisms of pulmonary vein reconnection after radiofrequency ablation of atrial fibrillation: the deterministic role of contact force and interlesion distance. $\mathbf{J}$ Cardiovasc Electrophysiol. 2014;25:701-8. 


\section{Appendix}

Participating centers (listed in alphabetical order):

Ospedale Sant' Anna, Ferrara (Matteo Bertini, Lina Marcantoni, Claudio Pratola); Ospedale Morgagni, Forlì (Alberto Bandini, Paolo Golia); Casa di Cura Montevergine, Mercogliano (Francesco Solimene, Giovanni Donnici); Casa di Cura Mediterranea, Napoli (Assunta Iuliano, Giuseppe Stabile); Policlinico Casilino, Roma (Leonardo Calò, Ermenegildo De Ruvo, Luigi Sciarra); Ospedale Sandro Pertini, Roma (Antonello Castro, Marialuisa Loricchio); Azienda Ospedaliera Santa Maria Nuova, Reggio Emilia (Nicola Bottoni, M Iori, F Quartieri); Città della Salute e della Scienza, Department of Medical Sciences, University of Turin (Matteo Anselmino, Federico Ferraris, Fiorenzo Gaita); Ospedale di Circolo e Fondazione Macchi, University of Insubria, Varese (Roberto De Ponti, Raffaella Marazzi, Lorenzo A Doni). 
Table I. Clinical characteristics of study population

\begin{tabular}{|c|c|c|c|c|}
\hline & $\begin{array}{l}\text { Study Population } \\
\text { (92 pts) }\end{array}$ & $\begin{array}{c}\text { Recurences } \\
\text { Group (17 pts) }\end{array}$ & $\begin{array}{l}\text { No recurences } \\
\text { Group (75 pts) }\end{array}$ & $\mathbf{P}$ \\
\hline Mean age (years) & $58 \pm 11$ (range 24-82) & $58 \pm 13$ & $58 \pm 10$ & 0.83 \\
\hline Male sex & $84 \%$ & $65 \%$ & $88 \%$ & 0.02 \\
\hline $\begin{array}{l}\text { Left atrium diameter } \\
(\mathrm{mm})\end{array}$ & $40 \pm 5$ (range33-55) & $39 \pm 7$ & $41 \pm 5$ & 0.39 \\
\hline $\begin{array}{l}\text { Left ventricle ejection } \\
\text { fraction }(\%)\end{array}$ & $58 \pm 8$ (range $40-65)$ & $60 \pm 2$ & $58 \pm 9$ & 0.34 \\
\hline Body mass index $>30$ & $5 \%$ & $0 \%$ & $6 \%$ & 0.33 \\
\hline Previous stroke/TIA & $4 \%$ & $0 \%$ & $5 \%$ & 0.33 \\
\hline Heart disease & $51 \%$ & $47 \%$ & $52 \%$ & 0.71 \\
\hline Hypertensive & $46 \%$ & $41 \%$ & $47 \%$ & 0.68 \\
\hline Ischemic & $7 \%$ & $0 \%$ & $8 \%$ & 0.23 \\
\hline Valvular & $4 \%$ & $6 \%$ & $4 \%$ & 0.73 \\
\hline $\begin{array}{l}\text { Dilated } \\
\text { cardiomyopathy }\end{array}$ & $4 \%$ & $0 \%$ & $5 \%$ & 0.33 \\
\hline Diabetes & $7 \%$ & $0 \%$ & $8 \%$ & 0.23 \\
\hline
\end{tabular}

Table II. Percentage of mean CF values in patients with and without AF recurrence.

\begin{tabular}{|l|c|c|c|}
\hline & A & B & C \\
& $5 \mathrm{~g}<\mathrm{CF} \leq 10 \mathrm{~g}$ & $11 \mathrm{~g}<\mathrm{CF} \leq 20 \mathrm{~g}$ & $21 \mathrm{~g}<\mathrm{CF} \leq 30 \mathrm{~g}$ \\
\hline No AF recurrence (75 & $38.7 \%(29)$ & $54.7 \%(41)$ & $6.6 \%(5)$ \\
pts) & & & \\
\hline AF recurrence (17 pts) & $6 \%(1)$ & $88 \%(15)$ & $6 \%(1)$ \\
\hline
\end{tabular}

$\mathrm{Pts}=$ patients; $\mathrm{CF}=$ contact force; $\mathrm{A}$ vs $\mathrm{B} \mathrm{p}=0.024$, B vs $\mathrm{C} \mathrm{p}=1 ; \mathrm{A}$ vs $\mathrm{C} \mathrm{p}=0.31$. 


\section{FIGURE LEGENDS}

Figure 1. Kaplan-Meier survival curve of patients free of AF during the 12-month follow-up (3month blanking period), according to the FTI quartilies . 